\title{
Is Bevacizumab a Direct Cause of Osteonecrosis of the Jaw like Bisphosphonate?
}

\author{
Morita Y*, Kashiwagi T, Takayama S, Nishimoto A, Imai T and Uzawa N \\ Department of Oral and Maxillofacial Surgery II, Osaka University Graduate School of Dentistry, Osaka, Japan
}

*Corresponding author: Morita Y, Department of Oral and Maxillofacial Surgery II, Osaka University Graduate School of Dentistry, Osaka, Japan.

To Cite This Article: Morita Y, Kashiwagi T, Takayama S, Nishimoto A, Imai T, Uzawa N. Is Bevacizumab a Direct Cause of Osteonecrosis of the Jaw like Bisphosphonate?. 2020 - 9(1). AJBSR.MS.ID.001354. DOI: 10.34297/AJBSR.2020.09.001354.

Received: 㠿 March 25, 2020; Published: 眥 June 02, 2020

\begin{abstract}
In 2014, the American Association of Oral and Maxillofacial Surgeons (AAOMS) published a revised position paper on osteonecrosis of the jaw in which cases caused by drugs other than bone resorption inhibitors, such as bevacizumab (an angiogenesis inhibitor), were labeled medicationrelated osteonecrosis of the jaw (MRONJ). Bevacizumab (Avastin) binds to endothelial growth factor (VEGF) preventing its attachment to receptors located on the surface of endothelial cells, thus inhibiting angiogenesis. Although the first case of ONJ caused by bevacizumab was described in 2008 , clinical cases of $\mathrm{ONJ}$ have since been described in which the use of bevacizumab is the only clear risk factor. This mini-review aims to summarize ONJ associated with bevacizumab, which was first recognized by the AAOMS in 2014.
\end{abstract}

\section{Introduction}

Osteonecrosis of the jaw (ONJ) is a bone disorder in which bone devitalization results from hypovascularity, hypocellularity, and local tissue hypoxia. Predisposing systemic factors for ONJ include duration of drug use, concomitant treatments, old age, and comorbidities. Anti-resorptive agent-related osteonecrosis of the jaw (ARONJ) is a condition characterized by the presence of exposed bone or bone that is visible through an intraoral or extraoral fistula in the maxillofacial region for a period of more than 8 weeks in patients receiving drugs without a history of head and neck radiation therapy. This definition includes cases of ARONJ associated with bisphosphonates (BPs) and denosumab. In 2014, the American Association of Oral and Maxillofacial Surgeons (AAOMS) published a revised position paper in which cases of osteonecrosis of the jaw caused by drugs other than bone resorption inhibitors, such as bevacizumab (an angiogenesis inhibitor), were labeled medication-related osteonecrosis of the jaw (MRONJ). This mini-review aims to summarize ONJ associated with bevacizumab, which was first recognized by the AAOMS in 2014.

\section{What is bevacizumab?}

Bevacizumab (Avastin) is a G1-humanised monoclonal antibody. It binds to endothelial growth factor (VEGF), inhibiting its attachment to the vascular endothelial growth factor (VEGF) receptor Flt-1 (VEGFR-1) and the kinase insert domain receptor (KDR) (VEGFR-2) located on the surface of endothelial cells. By neutralizing the biological activity of VEGF, tumor vascularization is reduced, thus inhibiting its growth [1]. Bevacizumab is indicated for patients with metastatic carcinoma of the colon or rectum, glioblastoma, lung cancer, and neoplastic neurovascular diseases. It has other non- neoplastic uses, including the treatment of certain ocular diseases [1].

\section{ONJ associated with bevacizumab}

ONJ caused by bevacizumab may be due to reduced VEGF action and the resulting decrease in angiogenesis. VEGF is essential to the formation, self-regulation, and survival of osteoclasts. Thus, disruption of this factor can produce a decrease in bone repair ability. Reduced VEGF action, together with microtrauma (produced by tooth brushing and chewing) or invasive dental treatments, may produce mandibular lesions and the development of ONJ $[2,3]$.

Although the first case of ONJ caused by bevacizumab was described in 2008 [4], clinical cases of ONJ have since been described $[1,3,5,6]$ in which the use of bevacizumab is the only clear risk factor (Table 1). 
Table 1: ONJ in patients treated with bevacizumab alone.

\begin{tabular}{|c|c|c|}
\hline Authors & Year & Location and cause of osteonecrosis (ON) \\
\hline Estilo et al. [4] & 2008 & $\begin{array}{c}\text { Spontaneous ON of mandible weeks after finishing } \\
\text { treatment }\end{array}$ \\
\hline Greuter et al. [5] & 2008 & ON of right side of maxilla post-extraction of teeth 25 and 26 \\
\hline Serra et al. [3] & 2009 & ON of right side of mandible post-extraction of tooth 37 \\
\hline Guarneri et al. [2] & 2010 & ON of mandible post-extraction \\
\hline & & Location and cause not described \\
\hline Hopp et al. [1] & 2012 & ON of right side of mandible post-extraction 2 years after \\
treatment
\end{tabular}

To date, only three studies have directly evaluated ONJ in patients treated with bevacizumab with or without BPs $[2,7,8]$. In a study by Aragon-Ching et al. [7], 55 were treated with BPs and bevacizumab and 5 with bevacizumab alone. Eleven patients (18.3\%) receiving the combination therapy developed ONJ, while those treated with bevacizumab alone did not. In a study by Guarneri et al. [2] in which 1309 patients were treated with bevacizumab (233 received BPs and bevacizumab, and 1076 received bevacizumab only), 4 patients developed ONJ: 2 with combined therapy and 2 with monotherapy. In contrast, Francini et al. [8] found no cases of ONJ after a mean of 19.7 months of follow-up in 59 patients treated with bevacizumab and BPs. Notably, none of these patients underwent invasive dental procedures during treatment, even if they had other risk factors, such as poorly fitting dentures, periodontal disease, or had undergone tooth extraction six weeks prior to treatment (Table 2).

\begin{tabular}{|c|c|c|c|c|}
\hline \multicolumn{2}{|c|}{ Table 2: Summary of incidence of osteonecrosis of the jaw (ONJ) in bevacizumab-containing therapy with/without bisphosphonate exposure. } \\
\hline Authors & Year & Total & $\begin{array}{c}\text { ONJ associated with } \\
\text { Bevacizumab alone }\end{array}$ & $\begin{array}{c}\text { ONJ associated with } \\
\text { Bevacizumab + BP }\end{array}$ \\
\hline Aragon-Ching et al. [7] & 2009 & 60 & $0 / 5$ & Nov-55 \\
\hline Guarneri et al. [2] & 2010 & 1309 & $2 / 233$ & $2 / 1076$ \\
\hline Francini et al. [8] & 2011 & 59 & $0 / 0$ & $0 / 59$ \\
\hline
\end{tabular}

\section{Conclusion}

We have reviewed the most recent literature describing cases of $\mathrm{ONJ}$ due to bevacizumab treatment. Whether bevacizumab is directly involved in the onset of ONJ remains controversial, since in most cases, ONJ has been linked to the use of this drug in combination with BP. Knowledge of the pathogenic mechanisms and clinical outcomes is essential for ensuring that the appropriate treatment is applied for these patients.

\section{Conflicts of Interest}

The authors have no conflicts of interest to disclose.

\section{References}

1. Hopp RN, Pucci J, Santos Silva AR, Jorge J.(2012) Osteonecrosis after administration of intravitreous bevacizumab. J Oral Maxillofac Surg 70(3): 632-635.

2. Guarneri V, Miles D, Robert N, Diéras V, Glaspy J, et al. (2010) Bevacizumab and osteonecrosis of the jaw: incidence and association with bisphosphonate therapy in three large prospective trials in advanced breast cancer. Breast Cancer Res Treat 122(1): 181-188.
3. Serra E, Paolantonio M, Spoto G, Mastrangelo F, Tetè S, et al. (2009) Bevacizumab-related osteneocrosis of the jaw. Int J Immunopathol Pharmacol 22(4): 1121-1123.

4. Estilo CL, Fornier M, Farooki A, Carlson D, Bohle G, et al. (2008) Osteonecrosis of the jaw related to bevacizumab. J Clin Oncol 26(24): 4037-4038.

5. Greuter S, Schmid F, Ruhstaller T, Thuerlimann B. (2008) Bevacizumabassociated osteonecrosis of the jaw. Ann Oncol. 19(12): 2091-2092.

6. Mohamed HAM, Nielsen CEN, Schiodt M. (2018) Medication related osteonecrosis of the jaws associated with targeted therapy as monotherapy and in combination with antiresorptives. A report of 7 cases from the Copenhagen Cohort. Oral Surg Oral Med Oral Pathol Oral Radiol 125(2): 157-163.

7. Aragon Ching JB, Ning YM, Chen CC, Latham L, Guadagnini JP, et al. (2009) Higher incidence of Osteonecrosis of the Jaw (ONJ) in patients with metastatic castration resistant prostate cancer treated with antiangiogenic agents. Cancer Invest 27(2): 221-226.

8. Francini F, Pascucci A, Francini E, Miano ST, Bargagli G, et al. (2011) Osteonecrosis of the jaw in patients with cancer who received zoledronic acid and bevacizumab. J Am Dent Assoc 142(5): 506-513. 